\title{
Clinical Study \\ Infection after Acute Ischemic Stroke: Risk Factors, Biomarkers, and Outcome
}

\author{
Katja E. Wartenberg, ${ }^{1}$ Anett Stoll, ${ }^{2}$ Andreas Funk, ${ }^{3}$ Andreas Meyer, ${ }^{4}$ \\ J. Michael Schmidt, ${ }^{5}$ and Joerg Berrouschot ${ }^{2}$ \\ ${ }^{1}$ Department of Neurology, Martin Luther University Halle-Wittenberg, Ernst-Grube-Strasse 40, 06120 Halle (Saale), Germany \\ ${ }^{2}$ Department of Neurology, Klinikum Altenburger Land, Am Waldessaum 10, 04600 Altenburg, Germany \\ ${ }^{3}$ Department of General Surgery, Klinikum Altenburger Land, Am Waldessaum 10, 04600 Altenburg, Germany \\ ${ }^{4}$ Central Laboratory, Klinikum Altenburger Land, Am Waldessaum 10, 04600 Altenburg, Germany \\ ${ }^{5}$ Division of Neurocritical Care, Neurological Institute, Columbia University College of Physicians and Surgeons, \\ 710 West 168th Street, New York, NY 10032, USA
}

Correspondence should be addressed to Katja E. Wartenberg, katja.wartenberg@medizin.uni-halle.de

Received 22 February 2011; Accepted 31 March 2011

Academic Editor: Byung Woo Yoon

Copyright (C) 2011 Katja E. Wartenberg et al. This is an open access article distributed under the Creative Commons Attribution License, which permits unrestricted use, distribution, and reproduction in any medium, provided the original work is properly cited.

Background. The activation of inflammatory cascades triggered by ischemic stroke may play a key role in the development of infections. Methods. Patients admitted with ischemic stroke within 24 hours were prospectively enrolled. Biomarkers of infection were measured on days 1, 3, and 5. The patients were continuously monitored for predefined infections. Results. Patients with infection were older (OR 1.06 per year, 95\% CI 1.01-1.11) and had a higher National Institute of Health Stroke Scale Score (NIHSS, OR 1.21, 95\% CI 1.10-1.34), localization in the insula, and higher stroke volumes on diffusion-weighted imaging. The maximum temperature on days 1 and 3, leukocytes, interleukin-6, lipopolysaccharide-binding protein on days 1, 3, and 5, C-reactive protein on days 3 and 5, and procalcitonin on day 5 were higher and HLA-DR-expression on monocytes on days 1, 3, and 5 lower in patients with infection. Age and NIHSS predicted the development of infections. Infection was an independent predictor of poor functional outcome. Conclusions. Severe stroke and increasing age were shown to be early predictors for infections after stroke.

\section{Introduction}

Infections complicating acute ischemic stroke contribute to mortality and poor functional outcome after stroke in most clinical studies [1-6]. Pneumonia occurs in 5-22\% and is the most common cause of death in stroke patients [1-8]. The risk of infection is highest in the acute phase after stroke [4] which may be attributed to stroke-induced immunodepression syndrome (SIDS). SIDS is characterized by loss of lymphocytes through apoptosis, shift of T-helper cell 1 to 2 cytokine production, decreased monocyte count and function, and interferon $\gamma$ deficiency which begins a few hours after ischemia and lasts for several weeks. These effects are associated with infection after stroke $[9,10]$. Biomarkers may facilitate an early diagnosis of infection in patients with acute ischemic stroke [11].
In this study we attempted to define biomarkers of early infection, identify early predictors of infection during the hospital course after acute ischemic stroke and the impact of infection on functional outcome after 3 months.

\section{Material and Methods}

2.1. Patient Population. Patients admitted to our stroke unit during one year were enrolled in the study if they (1) had symptoms and signs of an acute ischemic stroke, (2) were treated within 24 hours after symptom onset, (3) had a premorbid modified Rankin Scale score (mRS) of 0 to 1, and (4) gave informed consent. Patients were excluded from the study if they (1) had an intracranial hemorrhage, hypoglycemia, or other causes of a new focal deficit, (2) 
had contraindications against magnetic resonance imaging (MRI), (3) were taking antibiotics, (4) were immunocompromised by chemotherapy or acquired immunodeficiency syndrome, (5) had severe comorbidities, or (6) could not participate in the follow-up examination. The comprehensive stroke unit encompasses 8 monitored beds for stroke patients and 4 monitored beds with capacity for mechanical ventilation (neurointensive care unit). Patient recruitment was performed prospectively. The study was approved by the local ethics committee. Written informed consent was obtained from all patients (or their legal guardian) prior to participating in the study.

2.2. Clinical Management and Data. The patients were treated according to the guidelines of management of acute ischemic stroke $[12,13]$. The patients were screened on admission (day 1); demographic data, medical history including the presence of an infection in the last two weeks and medications prior to admission (specifically antibiotics) and risk factors, and vital signs were obtained. The temperature was measured continuously utilizing the temperature probe of the urinary catheter if placed or an axillary temperature probe. The maximum daily temperature was charted on days 1 and 3. Clinical examination encompassed a general evaluation, the National Institute of Health Stroke Scale (NIHSS), and mRS [14]. The patients received an electrocardiogram, a focused MRI (diffusionweighted imaging $=$ DWI and fluid attenuated inversion recovery imaging $=$ FLAIR), and a chest radiograph on day 1. Laboratory markers on admission included a complete blood count with differential, renal, and liver function tests, cardiac enzymes, and a urine analysis. The inflammatory markers, white blood cells (WBCs), C-reactive protein (CRP) $[15,16]$, procalcitonin (PCT), interleukin-6 (IL-6) [16-20], HLA-DR-expression on monocytes (HLADRM) [16, 19, 21], and lipopolysaccharide-binding protein (LBP) [22], were collected on days 1,3 , and 5 along with the mean body temperature (measured every 1-4 hours). The biomarkers were measured by chemical luminescence immunoassay (Immulite DPC Biermann, Siemens Diagnostics, Germany) (IL-6, LBP), automated immunofluorescent assay (Kryptor Brahms Diagnostica, Berlin, Germany), immunoturbidimetry (AU 600 Olympus, Dallas, TX, USA) (CRP), electrical impedance or flow cytometry (SE 9000 Sysmex, Digitana, Horgen, Switzerland) (WBC), and flow cytometry (EPICS XL, Beckman Coulter, Fullerton, CA, USA) (HLADRM). Another focused MRI (DWI and FLAIR) was performed on days 5-7. The infarction and edema volumes were calculated on DWI (day 1) and FLAIR (days 5-7) using the planimetry method [23]. All infections and procedures, presence of dysphagia from admission through day 5 , duration of hospital stay, the localization, and final etiology of the ischemic stroke according to the TOAST criteria [24] were recorded. Hospital procedures included the placement of urinary catheters in patients with urinary incontinence, requiring close monitoring of the fluid balance or mechanical ventilation; central lines in patients with impaired peripheral venous access, with sepsis or other causes for hemodynamic instability, requiring mechanical ventilation or vasopressors; mechanical ventilation for respiratory failure or airway protection.

2.3. Outcome Measures. The patients were screened for predefined infections until discharge: systemic inflammatory response (SIRS: two of the following criteria: temperature $>38^{\circ} \mathrm{C},<36^{\circ} \mathrm{C}$; heart rate $>90 / \mathrm{min}$; respiratory rate $>20 / \mathrm{min}, \mathrm{paCO}_{2}<32 \mathrm{~mm} \mathrm{Hg}$, or mechanical ventilation; WBC $>12 \mathrm{Gpt} / \mathrm{L},<4 \mathrm{Gpt} / \mathrm{L}$ or $10 \%$ blasts), sepsis (SIRS resulting from a presumed or known site of infection), upper respiratory tract infection ( 2 of the following criteria: purulent sputum, fever $>38^{\circ} \mathrm{C}$; WBC $>12 \mathrm{Gpt} / \mathrm{L},<4 \mathrm{Gpt} / \mathrm{L}$ or $10 \%$ blasts, no rales or rhonchi on auscultation and/or dullness on percussion, no requirement of supplemental oxygen), and pneumonia (purulent sputum, fever $>38^{\circ} \mathrm{C}$; WBC $>12 \mathrm{Gpt} / \mathrm{L},<4 \mathrm{Gpt} / \mathrm{L}$ or $10 \%$ blasts, new infiltrate on chest radiograph, requirement for supplemental oxygen), urinary tract infection (urinary analysis with evidence of WBC and nitrite, increased CRP or WBC $>12 \mathrm{Gpt} / \mathrm{L}$, $<4 \mathrm{Gpt} / \mathrm{L}$ or $10 \%$ blasts and/or clinical signs such as frequent urination, dysuria, flank pain, and/or positive urine culture), gastritis (confirmation by endoscopy, test for Helicobacter pylori). Pneumonia, SIRS, and sepsis were considered serious infections (requiring prolongation of hospitalization, causing neurological deterioration, and monitoring in the neurointensive care unit); upper respiratory, gastritis, and urinary tract infections (UTI) were defined as nonserious (no impact on neurological function, not requiring continuous monitoring). The infections were treated according to the national guidelines [25]. Patients with UTI according to the laboratory criteria not accompanied by fever and clinical symptoms of UTI received oral or intravenous fluids along with vitamin C (hospital standard).

Functional outcome was assessed at $90 \pm 14$ days using the mRS $(0=$ full recovery, $6=$ death $)[14]$; poor outcome was defined as death, moderate or severe disability (mRS score 3 to 6 ).

2.4. Statistical Analysis. Data analyses were performed with commercially available statistical software (17.0, SPSS, Chicago, IL, USA). The data were complete for all outcome variables. Univariate associations between demographic, clinical, radiological variables, inflammatory markers, and poor outcome were tested with Chi-square or Fisher's exact test for categorical variables, two-tailed $t$-test for normally distributed continuous variables, and Mann-Whitney $U$ test for nonnormally distributed continuous variables. Among similar clinical variables that were intercorrelated (involvement of the anterior or entire insula; stroke volume on DWI or FLAIR), only the variable with the highest odds ratio (OR) and smallest $P$ value in the binary logistic regression analysis was used as a candidate variable in the final multivariate model. Significant predictors of infection, serious infection, and poor outcome among the demographic, clinical, radiological variables, biochemical markers of day 1 were identified in a backward stepwise logistic regression model. $P$ values $<.05$, was considered significant. We also tested for 
TABLE 1: Univariate associations of demographic, baseline, vital signs, hospital complications, and procedures with the development of an infection and serious infection during the hospital stay.

\begin{tabular}{|c|c|c|c|c|c|}
\hline & No infection $N=55$ & Infection $N=39$ & $P$ & Serious infection $N=19$ & $P^{*}$ \\
\hline \multicolumn{6}{|c|}{ Demographics, clinical variables on admission } \\
\hline Age (years) & $69.2 \pm 1.6$ & $75.5 \pm 8.9$ & .006 & $74.6 \pm 2.2$ & NS \\
\hline Male sex & 28 & 15 & NS & 8 & NS \\
\hline $\begin{array}{l}\text { Time symptom onset to admission } \\
\text { (hours) }\end{array}$ & $5.2 \pm 0.7$ & $3.8 \pm 0.7$ & NS & $2.8 \pm 1.2$ & NS \\
\hline History of diabetes mellitus & 18 & 17 & NS & 9 & NS \\
\hline History of hypertension & 44 & 37 & NS & 18 & NS \\
\hline History of metabolic syndrome & 15 & 14 & NS & 5 & NS \\
\hline History of coronary artery disease & 24 & 20 & NS & 11 & NS \\
\hline History of stroke & 9 & 5 & NS & 3 & NS \\
\hline Admission NIHSS & $8.3 \pm 0.6$ & $13.3 \pm 0.9$ & $<.0001$ & $14.8 \pm 1.3$ & $<.0001$ \\
\hline Thrombolysis (IV and/or IA) & 18 & 15 & NS & 10 & NS \\
\hline $\begin{array}{l}\text { Systolic blood pressure on } \\
\text { admission }(\mathrm{mm} \mathrm{Hg})\end{array}$ & $161.0 \pm 4.1$ & $170.6 \pm 5.0$ & NS & $171.6 \pm 7.0$ & NS \\
\hline $\begin{array}{l}\text { Diastolic blood pressure on } \\
\text { admission }(\mathrm{mm} \mathrm{Hg})\end{array}$ & $85.2 \pm 2.5$ & $84.9 \pm 3.2$ & NS & $84.0 \pm 4.3$ & NS \\
\hline Heart rate on admission (bpm) & $81.6 \pm 2.0$ & $82.0 \pm 2.5$ & NS & $83.50 \pm 3.6$ & NS \\
\hline $\begin{array}{l}\text { Oxygen saturation on admission } \\
(\%)\end{array}$ & $95.6 \pm 0.4$ & $95.3 \pm 0.3$ & NS & $94.7 \pm 0.6$ & NS \\
\hline \multicolumn{6}{|c|}{ Hospital complications and procedures } \\
\hline Dysphagia & 8 & 23 & $<.0001$ & 16 & $<.0001$ \\
\hline Central line & 1 & 14 & $<.0001$ & 13 & $<.0001$ \\
\hline Urinary catheter & 16 & 38 & $<.0001$ & 19 & $<.0001$ \\
\hline Mechanical ventilation & 1 & 11 & $<.0001$ & 10 & $<.0001$ \\
\hline Length of hospital stay (days) & $9.9 \pm 0.7$ & $17.3 \pm 1.2$ & $<.0001$ & $20.7 \pm 2.1$ & $<.0001$ \\
\hline \multicolumn{6}{|c|}{ Radiological variables } \\
\hline DWI volume day $1\left(\mathrm{~cm}^{3}\right)$ & $11.3 \pm 3.5$ & $45.6 \pm 11.9$ & .002 & $58.0 \pm 20.2$ & .001 \\
\hline FLAIR volume day 5-7 $\left(\mathrm{cm}^{3}\right)$ & $15.8 \pm 4.2$ & $75.6 \pm 17.8$ & $<.0001$ & $105.3 \pm 32.1$ & $<.0001$ \\
\hline \multicolumn{6}{|l|}{ Location of stroke } \\
\hline Anterior insula included & 0 & 3 & .037 & 1 & NS \\
\hline Posterior insula included & 9 & 2 & NS & 1 & NS \\
\hline Entire insula included & 3 & 13 & $<.0001$ & 8 & .001 \\
\hline MCA territory & 40 & 29 & NS & 15 & NS \\
\hline ACA territory & 1 & 2 & NS & 1 & NS \\
\hline PCA territory & 19 & 7 & NS & 3 & NS \\
\hline Brain stem & 4 & 4 & NS & 2 & NS \\
\hline Cerebellum & 5 & 1 & NS & 1 & NS \\
\hline Right sided stroke & 25 & 16 & NS & 9 & NS \\
\hline Left sided stroke & 24 & 19 & NS & 8 & NS \\
\hline Bilateral stroke & 6 & 4 & NS & 2 & NS \\
\hline
\end{tabular}


TABle 1: Continued.

\begin{tabular}{|c|c|c|c|c|c|}
\hline & No infection $N=55$ & Infection $N=39$ & $P$ & Serious infection $N=19$ & $P^{*}$ \\
\hline \multicolumn{6}{|c|}{ Outcome } \\
\hline \multicolumn{6}{|c|}{ mRS at 3 months } \\
\hline 0 & 3 & 0 & $<.0001$ & 0 & $<.0001$ \\
\hline 1 & 11 & 1 & & 0 & \\
\hline 2 & 23 & 4 & & 1 & \\
\hline 3 & 15 & 11 & & 2 & \\
\hline 4 & 2 & 14 & & 10 & \\
\hline 5 & 1 & 2 & & 2 & \\
\hline 6 & 0 & 7 & & 4 & \\
\hline
\end{tabular}

Data are shown as number for dichotomized variables mean \pm standard error of the mean (SEM) for normally distributed continuous variables, or median (range) for abnormally distributed continuous variables. ${ }^{*} P$ value for analysis of serious infection versus no infection.

NIHSS: National Institute of Health Stroke Scale; IV: intravenous; IA: intra-arterial; DWI: diffusion weighted imaging; FLAIR: fluid attenuated inversion recovery imaging; MCA: middle cerebral artery; ACA: anterior cerebral artery; PCA: posterior cerebral artery; mRS: modified Rankin scale.

interactions between all independent predictors of outcome in the final model.

In a second step, age, NIHSS, and markers of infection were dichotomized at the threshold producing the largest area under the curve produced by a receiver operating characteristic (ROC) curve and were entered into a model to calculate the likelihood of infection or serious infection after acute ischemic stroke in order to identify highly predictive threshold values.

\section{Results}

Ninety-six patients were enrolled in the study from November 2007 through October 2008; 2 patients were excluded from the analysis for current antibiotic treatment upon stroke symptom onset. The mean age was $71.8 \pm 1.2$ years, and $46 \%$ of the patients were male. The baseline NIHSS was 9.5 (0-24). The cause of stroke was atherothrombosis in 35 (37\%) of patients, cardioembolism in $21(22 \%)$ of patients, lacunar infarction in $22(23 \%)$, and cryptogenic in $15(16 \%)$ of patients according to the TOAST criteria.

The rate of infection in all patients was 42\% (39/94 patients), and infection of those 20 patients (51\%) had a nonserious and 19 (49\%) a serious infection (Table 1). Pneumonia was diagnosed in $17(18 \%)$, catheter-related sepsis in $2(2 \%)$, urinary tract infections in $27(29 \%)$, upper respiratory tract infection in $1(1 \%)$, and gastritis in 5 patients (5\%). 10 patients (11\%) developed more than one infection during the hospital stay, and 29 patients (31\%) received antibiotics.

Several demographic, clinical, and radiological variables on admission and during the hospital stay as well as markers of infection on days 1, 3, 5 were associated with a development of an infection or serious infection during the hospital stay (Tables 1 and 2). Among them, inclusion of the insular region, only present in large territorial middle cerebral artery (MCA) infarction, was significantly linked with infection after ischemic stroke. Backward stepwise logistic regression $(P<.05)$ identified higher age and NIHSS on admission as the earliest independent predictors of infection (Table 3 ).
None of the laboratory markers of infection remained significant in the multivariate model. Maximum temperature as part of the definitions of infections was removed from the final model. Higher NIHSS was an independent predictor for development of a serious infection after stroke (Table 3).

To identify a threshold for the development of infection from a combination of significant admission predictors of infection and serious infection, the admission predictors were dichotomized according to their sensitivity and specificity in the ROC curve (infection: NIHSS $\geq 8.5$, age $\geq 72$ years, $\mathrm{LBP} \geq 17.5 \mathrm{mcg} / \mathrm{mL}, \mathrm{WBC} \geq 7.55 \mathrm{Gpt} / \mathrm{L}$, serious infection: NIHSS $\geq 8.5$, age $\geq 69.5$ years, LBP $\geq$ $18.5 \mathrm{mcg} / \mathrm{mL}$ ). However, their sensitivities and specificities ranged between $50 \%$ and $70 \%$. Therefore, a threshold for the development of an infection or serious infection with a high likelihood when the patient presents with a combination of certain factors and laboratory markers could not be found. However, PCT $\geq 0.07 \mathrm{ng} / \mathrm{mL}$, IL- $6 \geq 6.9 \mathrm{pg} / \mathrm{mL}$, and WBC $\geq 7.45 \mathrm{Gpt} / \mathrm{L}$ on day 5 were significantly associated with the presence of a serious infection (PCT and IL-6 with a sensitivity and specificity $>90 \%$, WBC with a sensitivity $>80 \%$, specificity $>70 \%$, Table 4 ).

Advanced age, higher NIHSS on admission, and larger final stroke volume (FLAIR day 5-7) as well as infection were independent predictors of moderate to severe disability and mortality at 3 months after stroke in the multivariate model $(P<.05)$. As NIHSS and final stroke volume were intercorrelated, FLAIR stroke volume was removed from the final model as NIHSS is easier and more rapidly obtained on admission (Table 5). Of those predictors, the presence of infection had the highest likelihood ratio (OR 6.34, 95\% CI $1.81-22.22)$.

\section{Discussion}

Our study demonstrates the higher likelihood of infection after ischemic infarctions for older patients with a more severe stroke (higher NIHSS on admission). Patients with a severe stroke are more prone to a serious infection during the hospital stay. Infection had a detrimental impact on 3 
TABLE 2: Univariate associations of laboratory markers of infection with the development of an infection and serious infection during the hospital stay.

\begin{tabular}{|c|c|c|c|c|c|c|}
\hline & No infection $N=55$ & Infection $N=39$ & $P$ & Serious infection $N=19$ & $P^{*}$ & Normal Range \\
\hline \multicolumn{7}{|c|}{ Markers of Infection } \\
\hline Mean temperature day $1\left({ }^{\circ} \mathrm{C}\right)$ & $36.7 \pm 0.1$ & $37.4 \pm 0.1$ & $<.0001$ & $37.4 \pm 0.2$ & .001 & \\
\hline Mean temperature day $3\left({ }^{\circ} \mathrm{C}\right)$ & $36.9 \pm 0.1$ & $37.7 \pm 0.1$ & $<.0001$ & $37.9 \pm 0.1$ & $<.0001$ & \\
\hline Procalcitonin day $1(\mathrm{ng} / \mathrm{mL})$ & $0.05 \pm 0.01$ & $0.29 \pm 0.23$ & NS & $0.53 \pm 0.01$ & NS & $<0.5$ \\
\hline Procalcitonin day $3(\mathrm{ng} / \mathrm{mL})$ & $0.05 \pm 0.01$ & $0.34 \pm 0.24$ & NS & $0.63 \pm 0.49$ & .04 & $<0.5$ \\
\hline Procalcitonin day $5(\mathrm{ng} / \mathrm{mL})$ & $0.05 \pm 0.01$ & $0.20 \pm 0.05$ & .002 & $0.35 \pm 0.10$ & $<.0001$ & $<0.5$ \\
\hline Interleukin-6 day 1 (pg/mL) & $7.35 \pm 1.8$ & $17.0 \pm 4.15$ & .019 & $21.6 \pm 7.5$ & .009 & $<6.0$ \\
\hline Interleukin-6 day $3(\mathrm{pg} / \mathrm{mL})$ & $9.0 \pm 1.5$ & $24.2 \pm 4.0$ & $<.0001$ & $36.25 \pm 6.8$ & $<.0001$ & $<6.0$ \\
\hline Interleukin- 6 day $5(\mathrm{pg} / \mathrm{mL})$ & $9.0 \pm 1.55$ & $37.4 \pm 11.3$ & .004 & $64.6 \pm 21.5$ & $<.0001$ & $<6.0$ \\
\hline $\begin{array}{l}\text { Lipopolysaccaride-binding } \\
\text { protein day } 1(\mathrm{mcg} / \mathrm{mL})\end{array}$ & $19.0 \pm 1.6$ & $26.6 \pm 2.8$ & .014 & $29.3 \pm 4.5$ & .008 & $<8.4$ \\
\hline $\begin{array}{l}\text { Lipopolysaccaride-binding } \\
\text { protein day } 3(\mathrm{mcg} / \mathrm{mL})\end{array}$ & $25.0 \pm 2.1$ & $44.7 \pm 6.1$ & .001 & $54.3 \pm 10.9$ & $<.0001$ & $<8.4$ \\
\hline $\begin{array}{l}\text { Lipopolysaccaride-binding } \\
\text { protein day } 5(\mathrm{mcg} / \mathrm{mL})\end{array}$ & $23.4 \pm 2.1$ & $50.9 \pm 6.0$ & $<.0001$ & $66.5 \pm 10.9$ & $<.0001$ & $<8.4$ \\
\hline C-reactive protein day $1(\mathrm{mg} / \mathrm{L})$ & $10.2 \pm 2.0$ & $19.2 \pm 5.2$ & NS & $22.8 \pm 7.1$ & .022 & $0-5.0$ \\
\hline C-reactive protein day $3(\mathrm{mg} / \mathrm{L})$ & $12.2 \pm 2.1$ & $46.7 \pm 9.45$ & $<.0001$ & $58.3 \pm 10.2$ & $<.0001$ & $0-5.0$ \\
\hline C-reactive protein day $5(\mathrm{mg} / \mathrm{L})$ & $10.0 \pm 1.4$ & $78.9 \pm 14.0$ & $<.0001$ & $113.7 \pm 24.9$ & $<.0001$ & $0-5.0$ \\
\hline White blood cells day 1 (Gpt/L) & $8.35 \pm 0.4$ & $10.3 \pm 0.5$ & .006 & $11.7 \pm 0.8$ & $<.0001$ & $4.0-11.0$ \\
\hline White blood cells day $3(\mathrm{Gpt} / \mathrm{L})$ & $8.3 \pm 0.8$ & $11.9 \pm 1.7$ & .034 & $11.3 \pm 0.8$ & .034 & $4.0-11.0$ \\
\hline White blood cells day $5(\mathrm{Gpt} / \mathrm{L})$ & $7.4 \pm 0.6$ & $9.6 \pm 0.5$ & .01 & $10.7 \pm 0.8$ & .006 & $4.0-11.0$ \\
\hline $\begin{array}{l}\text { Monozyte HLA-DR expression } \\
\text { day } 1(\%)\end{array}$ & $96.0 \pm 0.7$ & $92.9 \pm 1.5$ & .039 & $92.1 \pm 2.4$ & .034 & $>30$ \\
\hline $\begin{array}{l}\text { Monozyte HLA-DR expression } \\
\text { day } 3(\%)\end{array}$ & $95.1 \pm 1.2$ & $88.1 \pm 2.1$ & .002 & $89.1 \pm 2.0$ & .011 & $>30$ \\
\hline $\begin{array}{l}\text { Monozyte HLA-DR expression } \\
\text { day } 5(\%)\end{array}$ & $94.2 \pm 1.3$ & $88.5 \pm 2.0$ & .014 & $85.6 \pm 3.1$ & .004 & $>30$ \\
\hline
\end{tabular}

Data are shown as number for dichotomized variables mean \pm standard error of the mean (SEM) for normally distributed continuous variables, or median (range) for abnormally distributed continuous variables. ${ }^{*} P$ value for analysis of serious infection versus no infection.

TABle 3: Independent day 1 predictors of infection and severe infection.

\begin{tabular}{lcc}
\hline & OR $(95 \% \mathrm{CI})$ & $P$ \\
\hline \multicolumn{2}{c}{ Independent day 1 predictors of infection $(N=94)$} \\
\hline Age (years) & $1.06(1.01-1.11)$ & .020 \\
NIHSS & $1.21(1.10-1.34)$ & $<.0001$ \\
\hline \multicolumn{4}{c}{ Independent day 1 predictors of serious infection } \\
(versus no infection, $N=74)$ \\
NIHSS $\quad 1.28(1.23-1.46)$ & $<.0001$ \\
C-reactive protein $(\mathrm{mg} / \mathrm{L})$ & $1.03(1.0-1.06)$ & .053 \\
\hline
\end{tabular}

Binary logistic regression was used to calculate $P$ values and adjusted odds ratios (with 95\% confidence intervals).

NIHSS: National Institute of Health Stroke Scale.

months outcome after stroke. Aside from the randomized, double blind, placebo-controlled trials of prevention of infection after stroke with prophylactic antibiotic therapy [26-29] and case control studies [15, 16, 21], this is the first clinical study to prospectively investigate predefined
TABLE 4: Significant associations of day 5 markers of infection with serious infection.

\begin{tabular}{lcc}
\hline Day 5 markers of infection & OR $(95 \% \mathrm{CI})$ & $P$ \\
\hline $\begin{array}{l}\text { Procalcitonin day } 5 \geq \\
0.07 \mathrm{ng} / \mathrm{mL}\end{array}$ & $51.2(4.1-642.0)$ & .002 \\
$\begin{array}{l}\text { Interleukin }-6 \text { day } 5 \geq \\
6.9 \mathrm{pg} / \mathrm{mL}\end{array}$ & $33.6(2.1-547.0)$ & .014 \\
$\begin{array}{l}\text { White blood cells day } 5 \geq \\
7.45 \mathrm{Gpt} / \mathrm{L}\end{array}$ & $24.7(1.8-346.0)$ & .017 \\
\hline
\end{tabular}

Binary logistic regression was used to calculate $P$ values and adjusted odds ratios (with 95\% confidence intervals). The reference thresholds for dichotomization of the inflammatory markers were selected based on a receiver operating characteristic curve to identify a level that most accurately distinguished presence and absence of infection or severe infection.

biomarkers and predictors of infection by means of scheduled blood collections for 6 laboratory infection markers, neuroimaging, and daily screening for the presence of an infection, to differentiate between nonserious and serious infection, and with the intention to identify a threshold 
TABLE 5: Multivariate predictors of poor outcome (mRS 3-6) at 90 days.

\begin{tabular}{lcccc}
\hline & mRS 0-2 & mRS 3-6 & OR (95\% CI) & $P$ \\
& $N=42$ & $N=52$ & & \\
\hline Age (years) & $66.7 \pm 1.7$ & $75.9 \pm 1.3$ & $1.10(1.03-1.17)$ & .003 \\
NIHSS & $8.81 \pm 3.74$ & $66.77 \pm 13.82$ & $1.26(1.09-1.46)$ & .001 \\
Infection & 5 & 34 & $6.34(1.81-22.22)$ & .004 \\
\hline
\end{tabular}

Data are shown as number for dichotomized variables, mean \pm standard error of the mean (SEM) for normally distributed continuous variables or median (range) for abnormally distributed continuous variables. Binary logistic regression was used to calculate $P$ values and adjusted odds ratios (with 95\% confidence intervals) for the multivariate model.

NIHSS: National Institute of Health Stroke Scale; mRS: modified Rankin scale.

using a combination of variables associated with infection to reliably predict the occurrence of an infection during the hospital stay after stroke in combination with long-term functional outcome.

SIDS is characterized by reduced CD $3+\mathrm{T}$ cell, CD4+ and CD8+ T helper cell counts $[16,17,19]$, decreased interferon $\gamma$ production $[16,17]$, lymphopenia $[18,19]$, shift of $\mathrm{T}-$ helper 1 to T helper 2 cells [18], leukocyte depression [30] or elevation $[15,16,19,20]$, raised neutrophil counts $[16,20$, 21 ], decreased B- and T-cell counts, increased tumor necrosis factor (TNF) $\alpha[16,30]$, interleukin (IL)-5 [16], IL-6 [1620] and IL-10 levels [20, 30, 31], increased CRP levels [15, 16], decreased basophil and natural killer cell counts [21], increased monocyte counts $[16,20,21,31]$, deactivation of monocytes [18], and decreased HLA-DR density on monocytes $[16,19,21]$ in human or animal studies. In our study population mean temperature, IL-6, LBP, and WBC on day 1 were significantly higher and HLADRM significantly reduced in patients who developed an infection, just as in previous reports $[16,17,19,21]$. Additionally, CRP was also elevated on day 1 in patients who got a serious infection after stroke $[15,16,32]$. None of these markers of infections or PCT [16] proved sensitive enough on the day of symptom onset to reliably predict the development of an infection after stroke nor could a threshold for a combination of age, NIHSS, temperature, and laboratory markers on day 1 be identified. Another explanation may be that SIDS is still in the process of development at this early time point with different biomarkers following different time courses after the stress response of the hypothalamic-pituitary-adrenal axis $[9,10]$. In the patients who encountered an infection, the biomarkers seem to react by day 5 described by PCT $\geq 0.07 \mathrm{ng} / \mathrm{mL}$, IL- $6 \geq 6.9 \mathrm{pg} / \mathrm{mL}$, or WBC $\geq 7.45 \mathrm{Gpt} / \mathrm{L}$. However, most of the infections are diagnosed in the acute phase after stroke [4]. The role of insular cortex in SIDS remains unclear. A trend to a higher occurrence of infection after stroke with involvement of the insular cortex could not be confirmed in our multivariate model. Stroke severity, for example, higher NIHSS, may be more important for the development of infections; the insular cortex was involved in larger MCA territory infarctions exclusively. Cortical infarcts in the MCA territory were more frequent in patients with infections after ischemic stroke in a case control study [15].
The impact of age and stroke severity on the likelihood of infections after acute ischemic stroke was also seen in case control studies as a correlation of infarct size [21, 30], worse Scandinavian Stroke Scale on admission [15] or day 4 [32], or higher admission NIHSS $[16,20,31]$ with the presence of SIDS or infection.

The infection rate in our patient population amounted to $42 \%$. The frequency of infection was higher than reported in other ischemic stroke populations [1-8, 33, 34]. However, baseline NIHSS was higher 9.5 (0-24) in our stroke patients, and the patients were prospectively screened, whereas most of the study reports on infection after ischemic stroke are retrospective. The rate of pneumonia was $18 \%$, comparable to other reports $[1-8,34-37]$. Since all patients were treated in a certified stroke and neurointensive care unit, measures to prevent aspiration and ventilator-associated pneumonia in stroke patients might have kept the rate of pneumonia low while the overall rate of infection was high. The detrimental impact of infection on functional outcome at 3 months after stroke was confirmed in our dataset $[1-6,34]$.

The relationship of infection risk and more severe ischemic infarctions defined by higher NIHSS on admission or greater infarct volumes on neuroimaging seen in our patient population has been established [20, 21, 30, 31]. Several randomized trials demonstrated a reduction of infection rate in stroke patients by prophylactic administration of antibiotics but failed to show an impact on long-term functional outcome [26-29]. Two of the four studies enrolled patients with higher NIHSS scores $(>11)$ or who were bedridden on admission [26, 27]. Prophylaxis of infection with antibiotics in stroke patients is not recommended based on the results of those four studies, but the effect of close monitoring for infection and early initiation of antibiotics in older patients with severe ischemic stroke on clinical outcome should be investigated.

A number of limitations of our study should be mentioned: a patient sample size of 94 may have been too small to identify reliable thresholds of biomarkers for infection. There is a potential for referral bias in the overall patient profiles. Two patients presented with an infection on admission along with an acute ischemic stroke and were included in the study. The multivariate models may have lacked statistical power and validity underestimating possible effects of biomarkers and other potential predictors. The diagnosis of an infection was not time-locked in the dataset, therefore, no statement about the time course of markers of infection in relation to the occurrence of the infection can be made. While the biomarkers chosen to predict infection early are sensitive in the setting of infection or inflammation, they may not be specific for infection and/or immunodepression after acute ischemic stroke and have different time courses. Quantitative analysis of HLADRM was not available.

In summary, patients with more severe ischemic stroke and older age are more susceptible to the development of an infection during the hospital course. The biomarkers of infection studied may not be sensitive or specific to predict the occurrence of an infection on the day of stroke symptom onset and should not warrant the prophylactic use of antibiotics. Future trials of infection prevention and early 
initiation of treatment should include a careful selection of the study population based on stroke severity and age.

\section{Conflict of Interests}

The authors have no disclosures or conflict of interests related to the study. J. Berrouschot received speaker honoraria from Boehringer Ingelheim, Sanofi Aventis, Servier Germany, and Trommsdorff.

\section{References}

[1] K. S. Hong, D. W. Kang, J. S. Koo et al., "Impact of neurological and medical complications on 3-month outcomes in acute ischaemic stroke," European Journal of Neurology, vol. 15, no. 12, pp. 1324-1331, 2008.

[2] K. C. Johnston, J. Y. Li, P. D. Lyden et al., "Medical and neurological complications of ischemic stroke: experience from the ranttas trial. Ranttas investigators," Stroke, vol. 29, no. 2, pp. 447-453, 1998.

[3] I. L. Katzan, R. D. Cebul, S. H. Husak, N. V. Dawson, and D. W. Baker, "The effect of pneumonia on mortality among patients hospitalized for acute stroke," Neurology, vol. 60, no. 4, pp. 620-625, 2003.

[4] P. Langhorne, D. J. Stott, L. Robertson et al., "Medical complications after stroke: a multicenter study," Stroke, vol. 31, no. 6, pp. 1223-1229, 2000.

[5] B. Ovbiagele, N. K. Hills, J. L. Saver, and S. C. Johnston, "Frequency and determinants of pneumonia and urinary tract infection during stroke hospitalization," Journal of Stroke and Cerebrovascular Diseases, vol. 15, no. 5, pp. 209-213, 2006.

[6] D. L. Tirschwell, W. A. Kukull, and W. T. Longstreth Jr., "Medical complications of ischemic stroke and length of hospital stay: experience in Seattle, Washington," Journal of Stroke and Cerebrovascular Diseases, vol. 8, no. 5, pp. 336-343, 1999.

[7] R. J. Davenport, M. S. Dennis, I. Wellwood, and C. P. Warlow, "Complications after acute stroke," Stroke, vol. 27, no. 3, pp. 415-420, 1996.

[8] C. Sellars, L. Bowie, J. Bagg et al., "Risk factors for chest infection in acute stroke: a prospective cohort study," Stroke, vol. 38, no. 8, pp. 2284-2291, 2007.

[9] U. Dirnagl, J. Klehmet, J. S. Braun et al., "Stroke-induced immunodepression: experimental evidence and clinical relevance," Stroke, vol. 38, no. 2, pp. 770-773, 2007.

[10] A. Chamorro, X. Urra, and A. M. Planas, "Infection after acute ischemic stroke: a manifestation of brain-induced immunodepression," Stroke, vol. 38, no. 3, pp. 1097-1103, 2007.

[11] M. D. Gonsalves and Y. Sakr, "Early identification of sepsis," Current Infectious Disease Reports, vol. 12, pp. 329-335.

[12] P. A. Ringleb, M. G. Bousser, G. Ford et al., "Guidelines for management of ischaemic stroke and transient ischaemic attack 2008," Cerebrovascular Diseases, vol. 25, no. 5, pp. 457507, 2008.

[13] H. P. Adams Jr., G. Del Zoppo, M. J. Alberts et al., "Guidelines for the early management of adults with ischemic stroke: a guideline from the American heart association/American stroke association stroke council, clinical cardiology council, cardiovascular radiology and intervention council, and the atherosclerotic peripheral vascular disease and quality of care outcomes in research interdisciplinary working groups: the american academy of neurology affirms the value of this guideline as an educational tool for neurologists," Stroke, vol. 38, no. 5, pp. 1655-1711, 2007.

[14] C. Cincura, O. M. Pontes-Neto, I. S. Neville et al., "Validation of the national institutes of health stroke scale, modified rankin scale and barthel index in Brazil: the role of cultural adaptation and structured interviewing," Cerebrovascular Diseases, vol. 27, no. 2, pp. 119-122, 2009.

[15] A. J. Grau, F. Buggle, C. Steichen-Wiehn et al., "Clinical and biochemical analysis in infection-associated stroke," Stroke, vol. 26, no. 9, pp. 1520-1526, 1995.

[16] K. G. Haeusler, W. U. Schmidt, F. Fohring et al., "Cellular immunodepression preceding infectious complications after acute ischemic stroke in humans," Cerebrovascular Diseases, vol. 25, no. 1-2, pp. 50-58, 2008.

[17] J. Klehmet, H. Harms, M. Richter et al., "Stroke-induced immunodepression and post-stroke infections: 1SSessons from the preventive antibacterial therapy in stroke trial," Neuroscience, vol. 158, no. 3, pp. 1184-1193, 2009.

[18] K. Prass, C. Meisel, C. Hoflich et al., "Stroke-induced immunodeficiency promotes spontaneous bacterial infections and is mediated by sympathetic activation reversal by poststroke t helper cell type 1-like immunostimulation," Journal of Experimental Medicine, vol. 198, no. 5, pp. 725-736, 2003.

[19] A. Vogelgesang, U. Grunwald, S. Langner et al., "Analysis of lymphocyte subsets in patients with stroke and their influence on infection after stroke," Stroke, vol. 39, no. 1, pp. 237-241, 2008.

[20] A. Chamorro, S. Amaro, M. Vargas et al., "Interleukin 10, monocytes and increased risk of early infection in ischaemic stroke," Journal of Neurology, Neurosurgery and Psychiatry, vol. 77, no. 11, pp. 1279-1281, 2006.

[21] A. Hug, A. Dalpke, N. Wieczorek et al., "Infarct volume is a major determiner of post-stroke immune cell function and susceptibility to infection," Stroke, vol. 40, no. 10, pp. 32263232, 2009.

[22] J. Villar, L. Perez-Mendez, E. Espinosa et al., "Serum lipopolysaccharide binding protein levels predict severity of lung injury and mortality in patients with severe sepsis," PLOS ONE, vol. 4, no. 8, article e6818, 2009.

[23] C. Dieler, E. Frohlich, H. Bourquain, R. Holle, and R. von Kummer, "Simple volumetry of ischemic cerebral infarction using computerized tomography.interobserver and method comparison," Rofo, vol. 171, pp. 279-282, 1999.

[24] H. P. Adams Jr., B. H. Bendixen, L. J. Kappelle et al., "Classification of subtype of acute ischemic stroke: definitions for use in a multicenter clinical trial. Toast. trial of org 10172 in acute stroke treatment. ," Stroke, vol. 24, no. 1, pp. 35-41, 1993.

[25] hhttp://www.awmf.org/leitlinien/aktuelle-leitlinien/ll-liste/deutsche-gesellschaft-fuer-infektiologie-dgi.htm.

[26] S. A. Schwarz, C. Sick, S. Meairs, and M. G. Hennerici, "Effects of prophylactic antibiotic therapy with mezlocillin plus sulbactam on the incidence and height of fever after severe acute ischemic stroke: the mannheim infection in stroke study (miss)," Stroke, vol. 39, no. 4, pp. 1220-1227, 2008.

[27] H. P. K. Harms, C. Meisel, J. Klehmet et al., "Preventive antibacterial therapy in acute ischemic stroke: a randomized controlled trial," PLoS ONE, vol. 3, article e2158, 2008.

[28] A. H. J. Chamorro, V. Obach, M. Vargas et al., "The early systemic prophylaxis of infection after stroke study: a randomized clinical trial," Stroke, vol. 36, no. 7, pp. 1495-1500, 2005.

[29] Y. Lampl, M. Boaz, R. Gilad et al., "Minocycline treatment in acute stroke: an open-label, evaluator-blinded study," Neurology, vol. 69, no. 14, pp. 1404-1410, 2007. 
[30] A. Liesz, S. Hagmann, C. Zschoche et al., "The spectrum of systemic immune alterations after murine focal ischemia: immunodepression versus immunomodulation," Stroke, vol. 40, no. 8, pp. 2849-2858, 2009.

[31] A. Chamorro, S. Amaro, M. Vargas et al., "Catecholamines, infection, and death in acute ischemic stroke," Journal of the Neurological Sciences, vol. 252, no. 1, pp. 29-35, 2007.

[32] W. F. U. Palasik, W. Lechowicz, B. Czartoryska, M. Krzesiewicz, and A. Lugowska, "Assessment of relations between clinical outcome of ischemic stroke and activity of inflammatory processes in the acute phase based on examination of selected parameters," European Neurology, vol. 53, no. 4, pp. 188-193, 2005.

[33] J. Kwan and P. Hand, "Infection after acute stroke is associated with poor short-term outcome," Acta Neurologica Scandinavica, vol. 115, no. 5, pp. 331-338, 2007.

[34] F. H. Vermeij, W. J. Scholte op Reimer, P. De Man et al., "Stroke-associated infection is an independent risk factor for poor outcome after acute ischemic stroke: data from the Netherlands stroke survey," Cerebrovascular Diseases, vol. 27, no. 5, pp. 465-471, 2009.

[35] P. U. Heuschmann, P. L. Kolominsky-Rabas, B. Misselwitz et al., "Predictors of in-hospital mortality and attributable risks of death after ischemic stroke: the German stroke registers study group," Archives of Internal Medicine, vol. 164, no. 16, pp. 1761-1768, 2004.

[36] R. Hilker, C. Poetter, N. Findeisen et al., "Nosocomial pneumonia after acute stroke: implications for neurological intensive care medicine," Stroke, vol. 34, no. 4, pp. 975-981, 2003.

[37] U. Walter, R. Knoblich, V. Steinhagen, M. Donat, R. Benecke, and A. Kloth, "Predictors of pneumonia in acute stroke patients admitted to a neurological intensive care unit," Journal of Neurology, vol. 254, no. 10, pp. 1323-1329, 2007. 


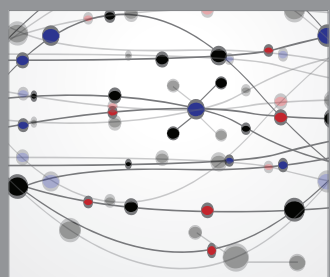

The Scientific World Journal
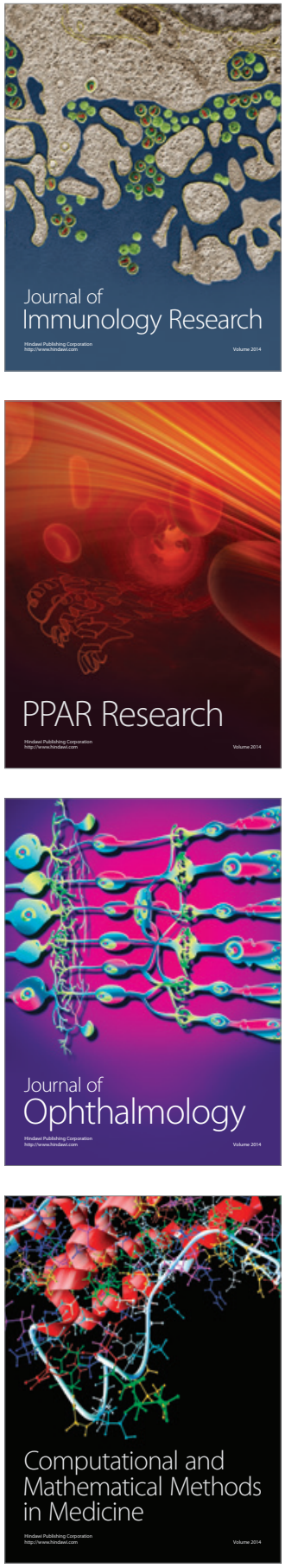

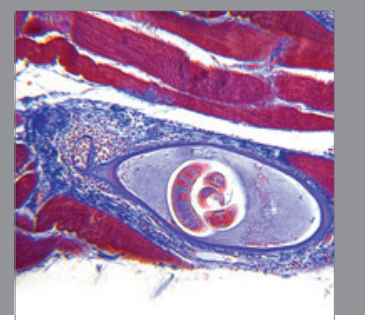

Gastroenterology

Research and Practice
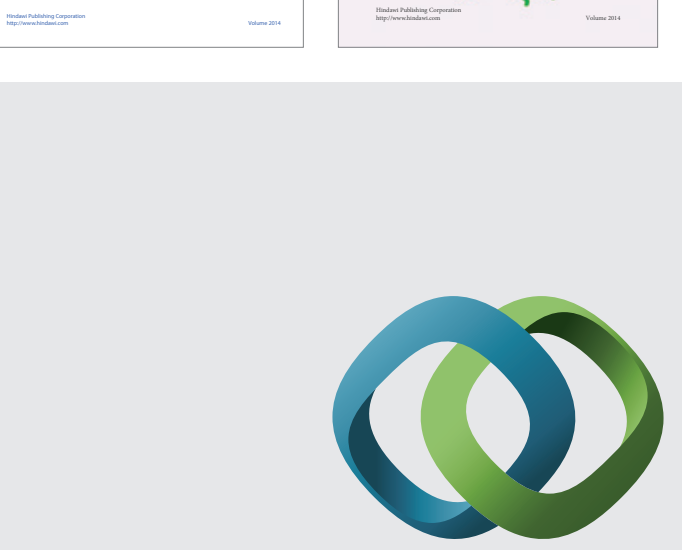

\section{Hindawi}

Submit your manuscripts at

http://www.hindawi.com
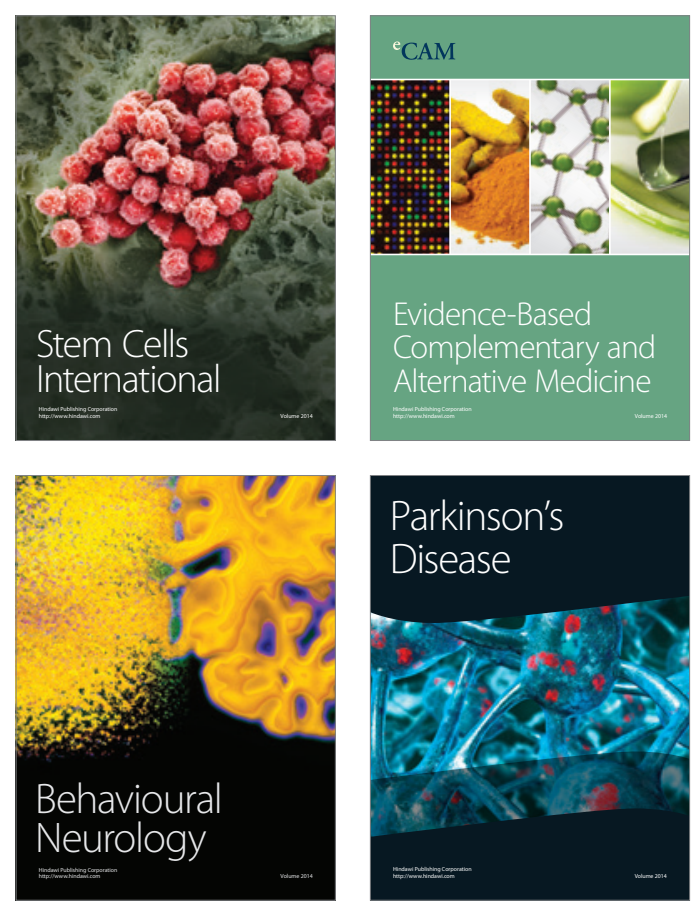

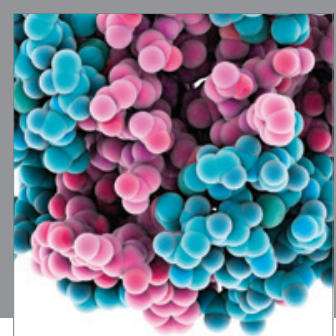

Journal of
Diabetes Research

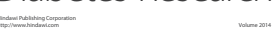

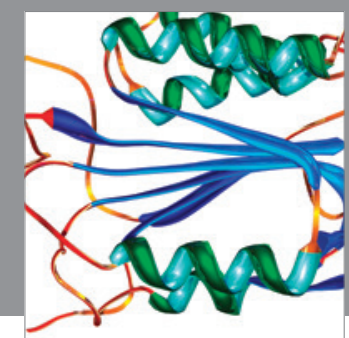

Disease Markers
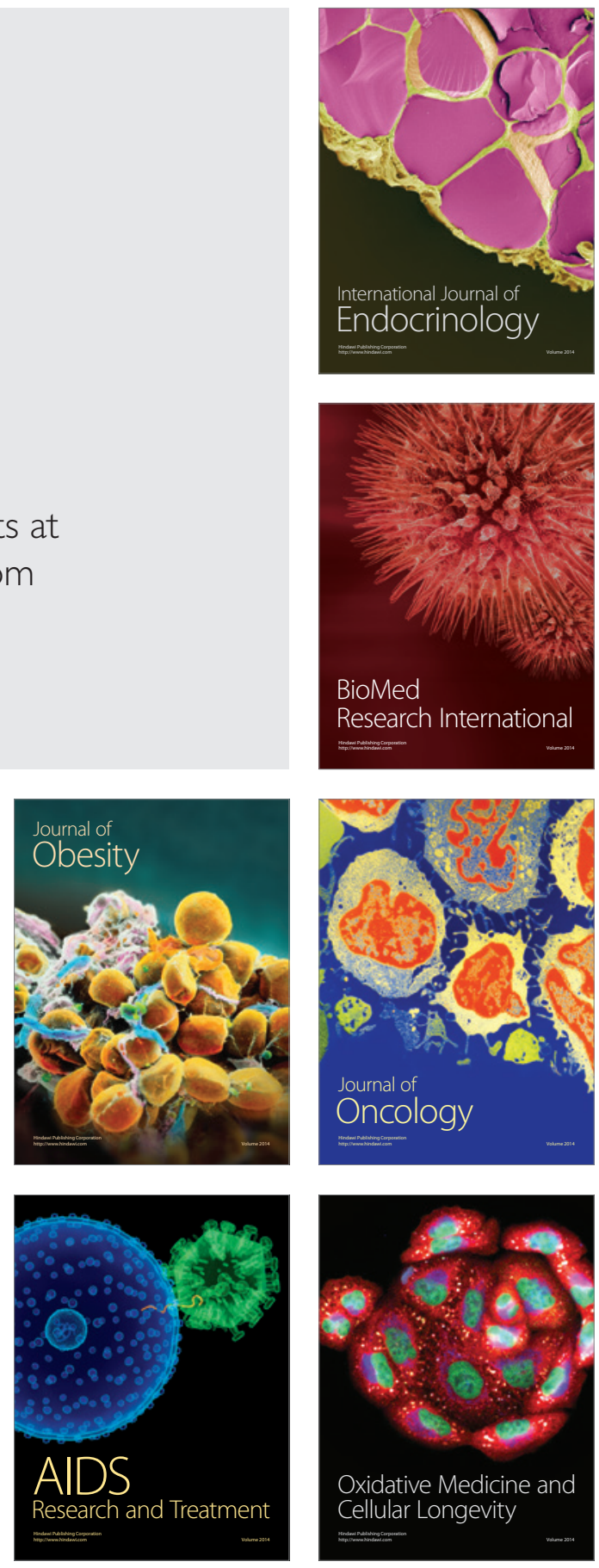